Original Research Article

\title{
Synthesis and Anti-inflammatory Activity of Some Newer Potential Isoxazoline Derivatives of Indole
}

Prajapati, T.R. ${ }^{1}$; Pandey, D. P. ${ }^{1}$; Gupta, Vipul' ${ }^{2}$ Joshi, Bhuwan ${ }^{3}$ and Dhingra, G. K. ${ }^{4}$

${ }^{1}$ Department of Chemistry, Govt. P. G. College, Uttarkashi

${ }^{2}$ Department of Chemistry, MIT, Moradabad

${ }^{3}$ Department of Chemistry, Govt. P. G. College, Haldwani

${ }^{4}$ Department of Botany, Govt. P. G. College, Rishikesh

Corresponding Author: drtilak.ram@rediffmail.com

A R T I C L E I N F O

Received: 02 August 2018 | Accepted: 14 October 2018 | Published Online: 31 December 2018

DOI: $10.31786 / 09756272.18 .9 .2 .213$

EOI: 10.11208/essence.18.9.2.213

Article is an Open Access Publication.

This work is licensed under Attribution-Non Commercial 4.0 International

(https://creativecommons.org/licenses/by/4.0/)

CThe Authors (2018). Publishing Rights @ MANU_ICMANU \& ESSENCE-IJERC.

\section{A B S T R A C T}

Some new 3-acetyl-2-carboxy-5-methoxy indole (1), 2-carboxy-5-methoxy-3-indolyl chalcones (2-6), 3-(2'-carboxy-5'-methoxyindol-3'-yl)-5-(substituted phenyl)-2-isoxazolines (7-11), 3-(2'carboxy-5'-methoxyindol-3'-yl)- 4-(substituted phenyl) aminomethyl-5-(substituted phenyl)-2isoxazolines (12-26) derivatives of indole have been synthesized in the present study. All the prepared compounds have been characterized by elemental and spectral analysis. All the above said compounds have been evaluated for their anti-inflammatory activity and some of them have been found as potential anti-inflammatory agents.

\section{K E Y W O R D S}

Indole | Chalcones | Isoxazolines | Anti-Inflammatory Activity

\section{I T A T I O N}

Prajapati, T.R.; Pandey, D. P.; Gupta, Vipul; Joshi, Bhuwan and Dhingra, G. K. (2019): Synthesis and Antiinflammatory Activity of Some Newer Potential Isoxazoline Derivatives of Indole. ESSENCE Int. J. Env. Rehab. Conserv. IX (1): 87-93. 


\section{Introduction}

The discovery of Indomethacin, Tenidap and sulindac as useful agents for clinical treatment of inflammatory disorders has led to exploration of indole with the aim to obtain better antiinflammatory agents. Furthermore, recently researches have revealed that chalcones, Schiff bases and isoxazoles of different pharmacodynamics moieties possess potent biological activities1 viz. anti-inflammatory 2-6, antimicrobial7, dengue virus inhibitors8, analgesic9, antipyretic10, sedative11, antihypertensive 12 , etc. In the light of these observations we have synthesized 3 - (2'-carboxy5'-methoxyindol-3'-yl) - 4- (substituted phenyl) aminomethyl - 5 - (substituted phenyl)-2isoxazolines (12-26) in order to evaluate their anti-inflammatory activity.

\section{Chemistry}

We describe here a convenient approach to the preparation of - 3 - (2'-carboxy-5'-methoxyindol3'-yl) - 4 - (substituted phenyl) aminomethyl-5(substituted phenyl)-2-isoxazolines (12-26). All the compounds were synthesized according to scheme I. 3-Acetyl-2-Carboxy-5-Methoxy Indole (1) was prepared by drop wise adding acetyl chloride (0.02 mole) to a solution of 2-Carboxy5 -Methoxy Indole in dry chloroform at 0-50c with constant stirring for 2 hours on magnetic stirrer in $70 \%$.

To a solution of compound 1 (0.01 mole) in methanol (50 $\mathrm{ml})$ o-methoxy, mhydroxybenzaldehyde was added in the presence of $2 \% \mathrm{NaOH}$ solution $(5 \mathrm{ml})$ at $0-5 \mathrm{oc}$. The reaction mixture was syirred for $6 \mathrm{hrs}$ on magnetic stirrer at room temperature and poured into ice water. The resulting solid was washed several times with water and recrystallized from methanol /water. The obtained compound 2-carboxy-5methoxy-3-indolyl (o-methoxy, mhydroxyphenyl) chalcones (2-6) yielded 65\%. 3-(2'-carboxy-5'-mehoxyindol-3'-yl)-5substituted phenyl) -2-isoxazolines (7-11) were prepared by mixing a solution of compounds 2-6 (0.01 mole) in methanol to hydroxylamine hydrochloride (0.01 mole) and solid $\mathrm{NaOH}(0.04$ $\mathrm{gm})$. This reaction mixture was refluxed for $8 \mathrm{hrs}$ and poured into cold water. The resulting mass was filtered, washed with water, dried and recrystallizes from benzene/petroleum ether. The yield was found $40 \%$.

The final compounds 3-(2'-carboxy-5'methoxyindol-3'-yl) - 4-(substituted phenyl) aminomethyl-5-(substituted phenyl)-2isoxazolines (12-26) were prepared from compounds 7-11. To a solution of compounds of 7-11 (0.01 mole) in methanol, formaldehyde (0.02 mole) and aniline (0.02 mole) were added drop wise. The reaction mixture was refluxed for $4 \mathrm{hrs}$. The excess of solvent was distilled off and poured into ice water. The separated solid was filtered, washed, dried and recrystallised from methanol and yielded $25 \%$.

\section{Scheme-1}
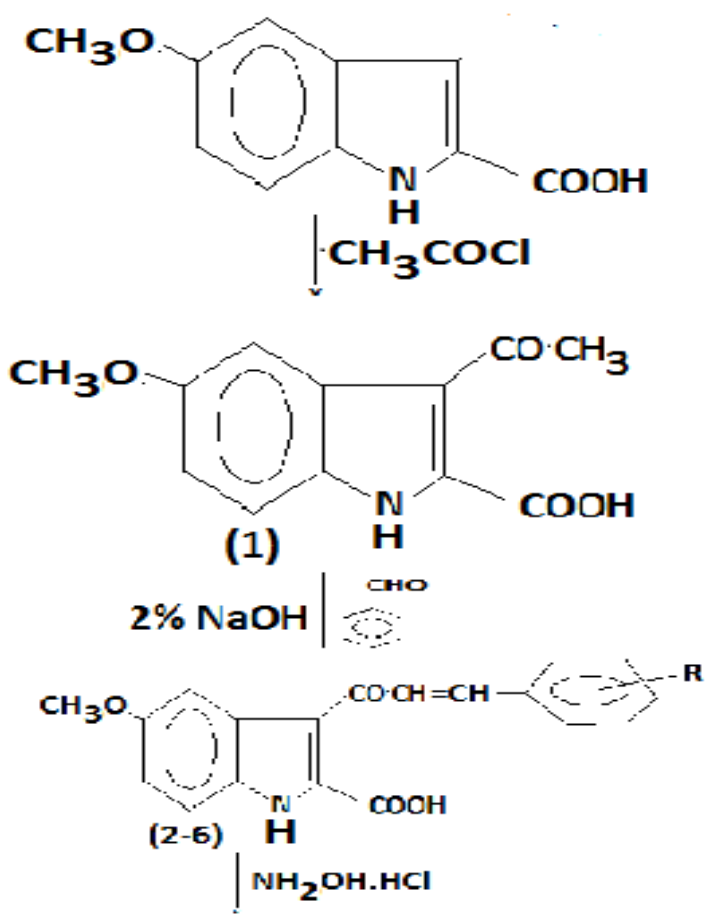


\section{Pharmacological results and discussion}

Newly synthesized compounds were studied for their anti-inflammatory activity against carrageenan-induced oedema. All the compounds were tested at a dose of $50 \mathrm{mg} / \mathrm{kg}$ given orally administrated. The results of study are shown in table 1. It is interesting to point out that all the compounds of the present series showed some antinflammatory activity. It may be concluded from the results that all the isoxazolines (7-11) possessed more potent anti-inflammatory activity than their corresponding chalcones (2-6). Aminoethyl derivatives i.e. Mannich compounds (12-26) exhibited better activity than chalcones but possessed less percentage inhibition of oedema than their isoxazoline derivatives (7-11). It has been observed that the compound 7 having methoxy at ortho and hyroxy group at meta position as substituent on phenyl ring was

\begin{tabular}{|c|c|c|c|c|}
\hline $\begin{array}{c}\text { Compound } \\
\text { No. }\end{array}$ & $\mathbf{R}$ & $\mathbf{R}^{\prime}$ & $\begin{array}{c}\text { Dose } \\
\mathrm{mg} / \mathrm{kg}\end{array}$ & $\%$ Anti-inflammatory Activity \\
\hline 2 & $\mathrm{o}-\mathrm{OCH}_{3}, \mathrm{~m}-\mathrm{OH}$ & - & 50 & $19.66 * * *$ \\
\hline 3 & $\mathrm{~m}-\mathrm{OH}$ & - & 50 & $18.97 * * *$ \\
\hline 4 & $\mathrm{H}$ & - & 50 & $16.39 * * *$ \\
\hline 5 & $\mathrm{~m}-\mathrm{N}\left(\mathrm{CH}_{3}\right)_{2}$ & - & 50 & $18.97 * * *$ \\
\hline 6 & $\mathrm{o}-\mathrm{OCH}_{3}$ & - & 50 & $18.65 * * *$ \\
\hline \multirow[t]{3}{*}{7} & $\mathrm{o}-\mathrm{OCH}_{3}, \mathrm{~m}-\mathrm{OH}$ & - & 25 & $43.23 * * *$ \\
\hline & & & 50 & $64.20 * * *$ \\
\hline & & & 100 & $71.20 * * *$ \\
\hline 8 & $\mathrm{~m}-\mathrm{OH}$ & - & 50 & $37.09 * * *$ \\
\hline 9 & $\mathrm{H}$ & - & 50 & 36.40 \\
\hline 10 & $\mathrm{~m}-\mathrm{N}\left(\mathrm{CH}_{3}\right)_{2}$ & - & 50 & $19.66 * * *$ \\
\hline 11 & $\mathrm{o}-\mathrm{OCH}_{3}$ & - & 50 & $31.95 * *$ \\
\hline 12 & $\mathrm{o}-\mathrm{OCH}_{3}, \mathrm{~m}-\mathrm{OH}$ & $\mathrm{H}$ & 50 & $33.50 * * *$ \\
\hline 13 & $\mathrm{o}-\mathrm{OCH}_{3}, \mathrm{~m}-\mathrm{OH}$ & $\mathrm{o}-\mathrm{Cl}$ & 50 & $27.00 * *$ \\
\hline 14 & $\mathrm{o}-\mathrm{OCH}_{3}, \mathrm{~m}-\mathrm{OH}$ & o-OCH $\mathrm{OH}_{3}$ & 50 & $35.33 * *$ \\
\hline \multirow[t]{3}{*}{15} & $\mathrm{~m}-\mathrm{OH}$ & $\mathrm{H}$ & 25 & 24.14 \\
\hline & & & 50 & $42.00 * *$ \\
\hline & & & 100 & $60.82 * * *$ \\
\hline 16 & $\mathrm{~m}-\mathrm{OH}$ & o-Cl & 50 & $32.00 * *$ \\
\hline 17 & $\mathrm{~m}-\mathrm{OH}$ & $\mathrm{o}-\mathrm{CH}_{3-}^{-}$ & 50 & $36.66^{* *}$ \\
\hline 18 & $\mathrm{H}$ & $\mathrm{H}$ & 50 & $27.00 * *$ \\
\hline 19 & $\mathrm{H}$ & $\mathrm{o}-\mathrm{Cl}$ & 50 & $36.00 * * *$ \\
\hline 20 & $\mathrm{H}$ & $\mathrm{o}-\mathrm{CH}_{3}$ & 50 & $22.00 * * *$ \\
\hline 21 & $\mathrm{o}-\mathrm{N}\left(\mathrm{CH}_{3}\right)_{2}$ & $\mathrm{H}$ & 50 & $15.20 * *$ \\
\hline 22 & $\mathrm{~m}-\mathrm{N}\left(\mathrm{CH}_{3}\right)_{2}$ & $\mathrm{o}-\mathrm{Cl}$ & 50 & $28.50 * * *$ \\
\hline 23 & $\mathrm{~m}-\mathrm{N}\left(\mathrm{CH}_{3}\right)_{2}$ & - & 50 & $19.66 * * *$ \\
\hline 24 & $\mathrm{o}-\mathrm{OCH}_{3}$ & $\mathrm{H}$ & 50 & $34.60 * *$ \\
\hline 25 & $\mathrm{~m}-\mathrm{OCH}_{3}$ & $\mathrm{o}-\mathrm{Cl}$ & 50 & $32.95 * * *$ \\
\hline 26 & $\mathrm{~m}-\mathrm{OCH}_{3}$ & $\mathrm{~m}-\mathrm{OCH}_{3}$ & 50 & $38.50 * * *$ \\
\hline \multirow[t]{3}{*}{ Phenylbutazone } & & & 25 & 15.00 \\
\hline & & & 50 & 38.90 \\
\hline & & & 100 & 65.20 \\
\hline \multirow[t]{3}{*}{ Indomethacin } & & & 25 & 38.30 \\
\hline & & & 50 & 49.40 \\
\hline & & & 100 & 63.00 \\
\hline
\end{tabular}

Table 1: Anti-inflammatory Activity of synthesized compounds (2-26) 
the most active (64.20) and it was studied at three graded doses $(25,50$ and $100 \mathrm{mg} / \mathrm{kg}$ orally) figure 2. The compound 15 exhibited most potent and dose dependant anti-inflammatory activity amongst the newly synthesized molecules (1226). Structural activity relationship showed that compounds in which isoxazoline moiety was substituted at 3-position of the indole nucleus exhibited significant activity. The compound having methoxy group at ortho and hydroxyl group at meta position as substituent at phenyl group elicited potent anti-inflammatory activity and when compound substituted with dimethyl amino group at meta position on phenyl ring, then the compounds showed lower anti-inflammatory activity. It has been observed that among the newly synthesized series the compound 21 having substituted with dimethyl amino group [-N (CH3)2] on phenyl ring at meta position exhibited least inhibition of rat's paw oedema (15.20\%). The compound 15 has shown better antiinflammatory activity $(42.00 \%)$ than the compound 21. The compound 7 and 15 were found to possess less ulcerogenic potentiality than phenylbutazone (UD50 of $7=258.66 \mathrm{mg} / \mathrm{kg}$, UD50 of $15=221.76 \mathrm{mg} / \mathrm{kg}$ and UD50 of phenylbutazone $=66.66 \mathrm{mg} / \mathrm{kg}$ ). Approximate lethal dose (ALD50) of the promising compounds under study were found to be more than 150 $\mathrm{mg} / \mathrm{kg}$.

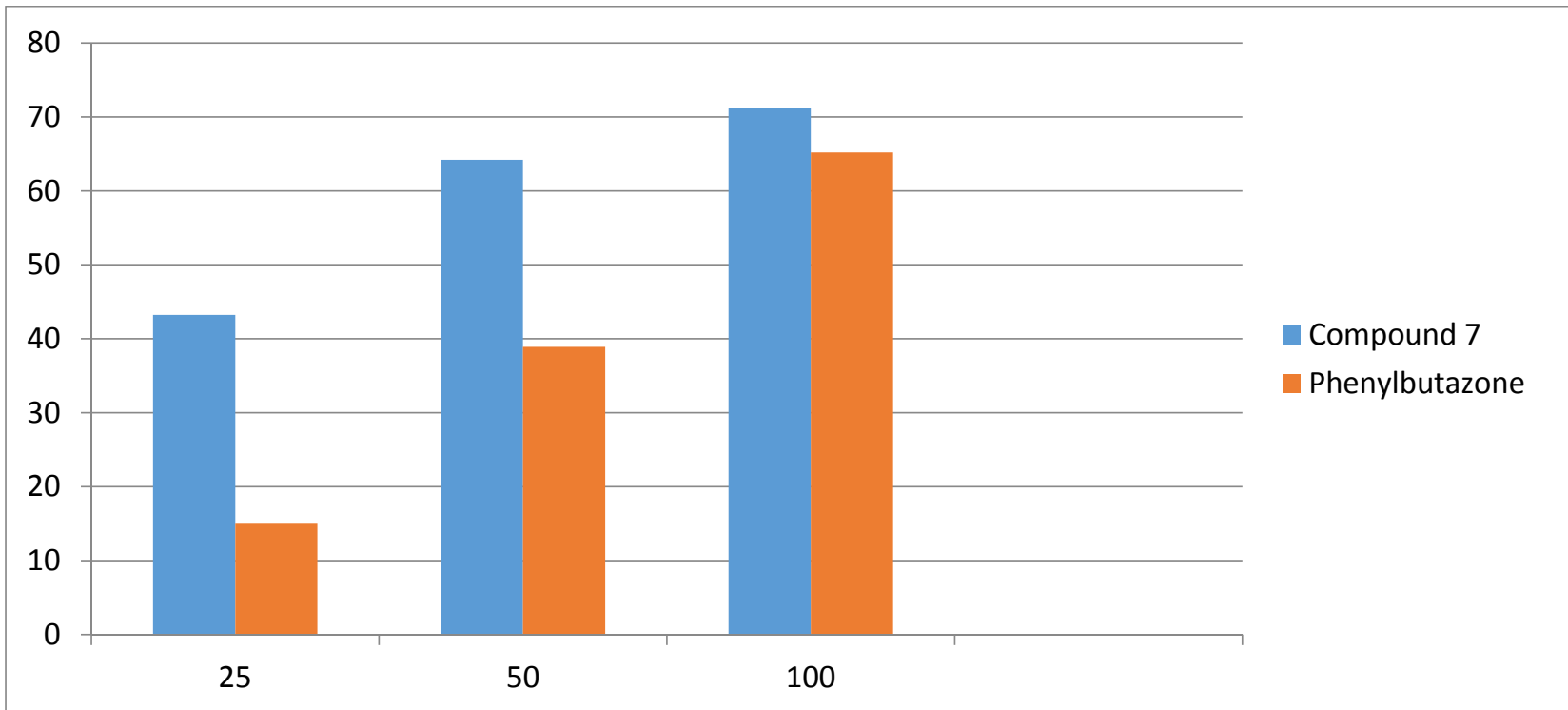

Figure 2: The bar diagram of $\%$ anti-inflammatory activity of compound 7 and phenylbutazone at three graded doses $(25,50$ and $100 \mathrm{mg} / \mathrm{kg}$ oral $)$.

\section{Conclusion}

The compounds were synthesized with the objective of developing better anti-inflammatory molecules with minimum CNS and CVS activities and optimal anti-inflammatory activity. The compound 7 showed maximum activity of $64.20 \%$ and compound $1542.005 \%$ at $50 \mathrm{mg} / \mathrm{kg}$ having less ulcerogenic as compared to the standard drug. Furthermore, behavioural activities did not elicit any appreciable change in gross behavior except that it induced mild retardation of locomotor activity at higher doses $(2000 \mathrm{~kg} / \mathrm{mg})$. Interesting enough, LD50 could not be determined as no animal died up to $2000 \mathrm{mg} / \mathrm{kg}$ dose, as it was maximum dose tested. Moreover, compound 15 has no significant activity on the cardiovascular system. It may, therefore, be concluded that the further study of this compound can lead to the development of a potent anti-inflammatory agent.

\section{Experimental Protocol}

\section{Chemistry}

Melting points were taken in open capillary tubes and are uncorrected. Analytical data of $\mathrm{C}, \mathrm{H}, \mathrm{N}$ were within $\pm 0.4 \%$ of the theoretical values. IR 
spectra were recorded on a Perkin-Elmer 157 spectrophotmeter in a $\mathrm{KBr}$ pellet (vmax cm-1). 1H-NMR spectra were recorded on a varian A90D with TMS as internal reference standard. Mass spectra were recorded on a JMS 300 instrument fitted with a JMS 2000 data system at $70 \mathrm{eV}$.

General procedure for the preparation of 3Acetyl-2-Carboxy-5-Methoxy Indole (1)

Acetyl chloride (0.02 mole) was added to a solution of 2-Carboxy-5-Methoxy Indole in dry chloroform at $0-50 \mathrm{c}$ with constant stirring for 2 hours on magnetic stirrer. The excess of solvent was distilled off and the separated mass was poured into ice water. The resulting solid was filtered and washed with water and recrystallized from methanol. IR (KBr, cm-1): 3453 (-OH of carboxylic group), $3145(=\mathrm{NH}), 3015$ (aromatic C-H). $1710(\mathrm{C}=\mathrm{O}), 1560$ (C-C aromatic ring). 1HNMR (CDCl3): $82.56(\mathrm{~s}, 3 \mathrm{H}, \mathrm{COCH} 3), 3.65(\mathrm{~s}, 3 \mathrm{H}$, Ar-OCH3), 6.82-7.32(m, 3H, Ar-H), 8.60(bs, 1H, -NH of indole, exchangeable with D2O), 12.10(ss, $1 \mathrm{H}, \mathrm{COOH}$ exchangeable with D2O) ppm. MS: $[\mathrm{M}]+\mathrm{m} / \mathrm{z} 233$.

2-carboxy-5-methoxy-3-indolyl (o-methoxy, mhydroxyphenyl) chalcones (2)

The solution of compound 1 (0.01 mole) in methanol $(50 \mathrm{ml})$ was added o-methoxy, $\mathrm{m}$ hydroxybenzaldehyde in the presence of $2 \%$ $\mathrm{NaOH}$ solution $(5 \mathrm{ml})$ at $0-5 \mathrm{oc}$. The reaction mixture was stirred for $6 \mathrm{hrs}$ on magnetic stirrer at room temperature and poured into ice water. The resulting solid was washed several times with water and recrystallised from methanol/water. IR (KBr, cm-1): 3165 (=NH), 3030 (aromatic C-H). $1620(\mathrm{CH}=\mathrm{CH}), 1545$ (C-C aromatic ring). $1 \mathrm{H}-$ $\mathrm{NMR}(\mathrm{CDCl} 3): \delta 3.55$ (s,6H,2 x Ar-OCH3), 5.85 $(\mathrm{d}, \mathrm{J}=7 \mathrm{~Hz}, 1 \mathrm{H}, \mathrm{COCH}=), 6.87(\mathrm{~d}, \mathrm{~J}=7 \mathrm{~Hz}$, $1 \mathrm{H}=\mathrm{CHAr}), 7.15-7.90(\mathrm{~m}, 6 \mathrm{H}, \mathrm{ArH}), 8.65(\mathrm{bs}, 1 \mathrm{H}$, -NH of indole, exchangeable with D2O), 9.20 (s, $1 \mathrm{H}, \mathrm{Ar}-\mathrm{OH}$, exchangeable with $\mathrm{D} 2 \mathrm{O}$ ), 12.00 (ss, $1 \mathrm{H}, \mathrm{COOH}$ exchangeable with $\mathrm{D} 2 \mathrm{O}$ ) ppm. MS:
$[\mathrm{M}]+\mathrm{m} / \mathrm{z} 367$. The compounds 3-6 were prepared similarly and characterized.

\section{3-(2'-carboxy-5'-mehoxyindol-3'-yl)-5- (substituted phenyl) -2-isoxazolines (7)}

The compound 7 was prepared by mixing a solution of compounds 2-6 (0.01 mole) in methanol with hydroxylamine hydrochloride (0.01 mole) and solid $\mathrm{NaOH}(0.04 \mathrm{gm})$. This reaction mixture was refluxed for $8 \mathrm{hrs}$ and poured into cold water. The resulting mass was filtered, washed with water, dried and recrystallized from benzene/petroleum ether. IR ( $\mathrm{KBr}, \mathrm{cm}-1)$ : 3135 (=NH), 3010 (aromatic C-H), $2910(\mathrm{CH} 2), 1670$ (CH), 1530 (C-C aromatic ring), 1240 (C-O-C). 1H-NMR(CDCl3) : $\delta 3.86$ (s,6H,2 x Ar-OCH3), $5.72(\mathrm{~d}, \mathrm{~J}=7 \mathrm{~Hz}, 2 \mathrm{H}, \mathrm{CH} 2$ of isoxazole ring), 6.55 (t, J=7Hz, $1 \mathrm{H}=\mathrm{CHAr}), 6.89-7.92(\mathrm{~m}, 6 \mathrm{H}, \mathrm{ArH})$, $8.60(\mathrm{~s}, 1 \mathrm{H},-\mathrm{NH}$ of indole, exchangeable with D2O), $9.68(\mathrm{~s}, 1 \mathrm{H}, \mathrm{Ar}-\mathrm{OH}$, exchangeable with D2O), 12.10 (ss, 1H, COOH exchangeable with D2O) ppm. MS: $[\mathrm{M}]+\mathrm{m} / \mathrm{z} 382$. The compounds 8-11 were prepared similarly and characterized.

3-(2'-carboxy-5'-methoxyindol-3'-yl) - 4(substituted phenyl) aminomethyl-5(substituted phenyl)-2-isoxazolines (15)

The one of the most potent final compounds, 15 was prepared from compound 8 . The solution of compounds of 8 (0.01 mole) in methanol was condensed with formaldehyde (0.02 mole) and aniline $(0.02$ mole). The reaction mixture was refluxed for $4 \mathrm{hrs}$. The excess of solvent was distilled off and poured into ice water. The separated solid was filtered, washed, dried and recrystallized from methanol. IR ( $\mathrm{KBr}, \mathrm{cm}-1)$ : $3120(=\mathrm{NH}), 3050$ (aromatic C-H), $2920(\mathrm{CH} 2)$, $1630(\mathrm{C}=\mathrm{N}), 1550(\mathrm{C}-\mathrm{C}$ of aromatic ring), 1240 $(\mathrm{C}-\mathrm{O}-\mathrm{N}), 1220(\mathrm{CN}) .1 \mathrm{H}-\mathrm{NMR}(\mathrm{CDCl} 3): \delta 2.95$ (m,1H, CHCH2), 3.85 (s,3H,Ar-OCH3), 5.63 (s, $1 \mathrm{H}$, NHAr, exchangeable with D2O), $6.62(\mathrm{t}$, $\mathrm{J}=6 \mathrm{~Hz}, 2 \mathrm{H}, \mathrm{CH} 2), 7.00-8.05(\mathrm{~m}, 13 \mathrm{H}, 12 \mathrm{H}, \mathrm{ArH}$, 1H, CHAr, exchangeable with D2O), 12.10 (ss, $1 \mathrm{H}, \mathrm{COOH}$ exchangeable with $\mathrm{D} 2 \mathrm{O}$ ) ppm. MS: 
$[\mathrm{M}]+\mathrm{m} / \mathrm{z}$ 457. The compounds 12-14 and 16-26 were prepared similarly and characterized.

\section{Pharmacology}

\section{Anti-inflammatory Activity}

Freshly prepared suspension of carrageenan $(0.05$ $\mathrm{ml}$ of $1.0 \%$ solution in $0.9 \%$ saline) was injected under the planter aponeurosis of the right paw of rats by method of Winter et al 1962 . One group of ten rats was kept control and the animals of other group were pretreated with test drugs given orally one hour before the carrageenan injection. The foot volume was measured before and $3 \mathrm{hr}$ after the carrageenan injection by the micropipette method described by Buttle et al 1957 . The mean increase in the paw volume in each group was calculated according to the following formula-

Anti-inflammatory activity percentage $=1-\mathrm{Vt} /$ Vc x 100.

Where $\mathrm{Vt}$ and $\mathrm{Vc}$ are the oedem volumes in the drug treated and the control groups. Phenylbutazone was used as standard drug for comparison.

\section{Ulcerogenic Activity 15}

Adult albino rats of either sex were divided into groups of ten animals each. Pregnancy was excluded in female rats. The rats were fasted for 24 hours prior to the administration of drugs. Water was allowed ad libitum to the animals. Three graded doses of most active compound of the series and phenylbutazone were given intraperitoneally and the animals were sacrificed 8 hours after drug treatment. The stomach, duodenum and jejunam were removed and examined with the hand lens for any evidence of (a) shedding of epithelium, (b) petechial and frank haemorrhages and (c) erosion or discrete ulceration with or without perforation. The presence of any one of these was taken as an evidence of ulcerogenic activity.

\section{Cardiovascular Activity16}

Cats were anaesthetized with L-chloralose (80 $\mathrm{mg} / \mathrm{kg}$ ) and maintained on positive pressure artificial respiration. Blood pressure was recorded from the right common carotid artery with the help of a statham tranducer on one channel of a polygraph (Polyrite, India). The heart rate was calculated from the pressure pulse tracing in all the experiments. The most active compound of the series was injected intravenously through an indevelling polyethylene cannula and effect of the agent on resting blood pressure, heart rate and presser responses evoked either by bilateral carotid occlusion or norepinephrine (0.5-2.0 $\mathrm{mg} / \mathrm{kg}$ ) injection was studied.

\section{Behavioural studies and determination of LD50}

The compound which showed maximum antinflammatory activity against carrageenaninduced oedema was investigated in detail for its behavioural effects and acute toxicity [approximate acute LD50] by the method of Smith17 inrats.

Following the oral administration of the test drug in one group and the same volume of normal saline in another group, the rats were placed in observation cages. During the 3 hours of observation period of animals were observed for locomotor activity, hind limb weakness, head drops, loss of righting reflex and reactivity to sensory stimuli, 24 hours later the mortality, if any, was noted.

\section{Acknowledgement}

We are thankful for Principal, Govt. P.G. College, Utarkashi, for providing all facilities of research work, CDRI, Lucknow for spectral, analytical analysis and Department of Medical Lab Technology, Govt. P.G. College, Rishikesh for biological activity.

\section{References}

Aralihalli, S.; Ramappa, R.; Gowdru, H. B.; Gummanar, N.; Sonnappa, R. and 
Malavalli, M. K. (2016): Amer. J. Hetero.

Chem, 2(1): 13-19.

Archibald; Leheup, J. (1978): Chem. Abstr, 85(11): 77996s.

Bardiot, D.; Koukni, M. and Smets, W. (2018): J. Med. Chem, 61(18): 8390-8401.

Buttle, G. N.; Arey, P. F. D.; Howard, E. M. and Kelletic, D. M. (1957): Nature (London), 176,629 .

Claude, F.; Michel, T.; Guy, R. and Claude, G. (1975): Chem. Abstr, 83(5): 43187x.

Friedrich, L. B.; Andersen, W. (1973): Chem. Abstr, 79(7): 42339d.

Herbst， D. R. (1970): Chem. Abstr, 72(19): 100508 b.

Kaushik, N. K.; Kaushik, N.; Attri, P.; Kumar, N.; Kim, C. H.; Verma, A. K. and Choi, E. H. (2013): Molecules, 18(6): 6620-6662.

Khan, K. M.; Rahim, F.; Muhammad, T.; Haider, S. M.; Perveen, S.; Khalid, A. S.; Abdalla, O. M.; Soomro, S. and Voelter, W. (2015): Bioorganic Chemistry, 60, 118-122.

khedekar, P. B.; Kerzare, D. and Menghani, S. (2018): Ind, J. Pharm. Educ.Res, 52(1): 110-114.

Kumar, A.; Gurtu, S.; Sinha, J. N.; Bhargava, K. P. and Shankar, K. (1985): Eur. J. Med. Chem. Chin. Ther, 20 (1): 1985, 95.
Ludnila, F.; Jaroslava, G.; Zdenec, R. and Oldrich, N. (1981): Chem. Abstr, 95(1): 7061r.

Quazi, I.; Sastry, V. G. and Ansari, J. A. (2017): 8(3): 1145-52.

Smith, C. C. (1950): J. Pharmacol, Exp. Therap., 100, 408.

Sonar, V. N.; Khadar, Y. S. and Sreenivasulu, N. (2001): Ind. J. Heterocycl. Chem, 10(4): 299-302.

Verma, M.; Sinha, J. N.; Gujrati, V. R.; Bhalla, T. N.; Bhargava, K. P. and Shankar, K. (1981): Pharm Res. Comm. , 13 (10): 967.

Winter, C. A.; Fistley, E. A. and Nuss, C. M. (1962): Proc. Soc. Exp. Biol. (New York), $544,111$. 